\title{
COMPARACION ENTRE LAS POBLACIONES DE BACTERIAS FOTOTROFICAS DEL AZUFRE DESARROLLADAS EN DIFERENTES COLUMNAS DE WINOGRADSKY MODIFICADAS
}

\author{
I.V. Pibemat y C.A Abella \\ Institut d'Ecologia Aquàtica. Universitat de Girona. PI. Hospital, 6, E-17071 Girona
}

Palabras clave: columna de Winogradsky, método laboratorio, bacterias folotróficas verdes del azutre, Cromatiáceas, sucesión.

\begin{abstract}
Planktonic phototrophic sulfur bacteria are common in many meromictic as well as monomictic lakes with anaerobic bottom waters during stratification. Phototrophic sulfur bacteria use mainly reduced sulfur compounds as electron donors in their photosymthesis. The Winogradsky column was a traditional method for studying microbial ecology in laboratoy. The growth of the phototrophic sulfur bacteria was studied in a modified Winogradsky column. The column consists of a cylinder of Pyrex glass of $130 \mathrm{~cm}$ length and $11 \mathrm{~cm}$ width filled with lake water of "Riera Castellana" stream and sediment from Vila lake (Banyoles, Girona). It was cooled at the bottom and heated above in order to form stratification in the water column. The illumination comes from above to form a vertical ligth-intensity gradient. The column was equiped with probes for measuring various physical and chemical factors.

The differential characteristics between two columns were the volume of sediment, the illumnination cycle and the water temperature. In relation to sediment, different processes took place according to temperature. At the column with more sediment and $25^{\circ} \mathrm{C}$ of water temperature, higher sulphide concentration was measured $(500 \mu \mathrm{M})$. Chlorobium limicola was the population of phototrophic sulfur bacteria enriched. In the column with less sediment and lower water temperature $\left(15^{\circ} \mathrm{C}\right)$, the sulphide concentration measured was lower and the population of phototrophic sulfur bacteria developed was a Chromatiaceae, Thiocapsa roseopersicina and a green phototrophic sulfur bacteria, Chlorobium limicola f. thiosulfatophilum.
\end{abstract}

\section{INTRODUCCION}

Las bacterias fototrólicas del azufre son frecuentes en muchos lagos meromicticos y holomicticos con un volumen de agua anóxica durante la estratificación. La columna de Winogradsky es utilizada tradicionalmente en ecología microbiana como un microsistema de laboratorio con un ciclo de materia cerrado y una fuente de energia extema, la luz solar. La utilidad de la columna radica en facilitar la obsenvación y el estudio de microorganismos anaeróbicos, bacterias fototróficas del azufre y microorganismos asociados quienes, en condiciones naturales, se localizan en la zona prolunda del lago (hipolimnion).

Estos microorganismos constituyen los productores primarios en los ambientes anóxicos eutróficos jugando un importante papel en el reciclaje de la materia en estos ecosistemas naturales (Brock y Madigan, 1988).

La construcción de la columna de Winogradsky tradicional se realiza en un cilindro de vidrio con sedimento anóxico y agua del lago. Al sedimento se le añaden celulosay sullato cálcico para facilitar la actividadmicrobiana. A los quince dias, el metabolismo heterotrófico oxidativo ha agotado el oxígeno disuelto en el agua de la zona más próxima al sedimento, hecho que dificulta su desarrollo al mismo tiempo que facilita la sulfato reducción con la producción de $\mathrm{H}_{2} \mathrm{~S}$. El sulthidrico proporciona una disminución del potencial redox y si las condiciones de luz són adecuadas, facilitarán el establecimiento de poblaciones fototrólicas del azufre (Bielb y Pfennig, 1978).

Las columnas de laboratorio se utilizan en estudios de ecologia por presentar un modelo en miniatura del 
ecosistema natural, fácilmente accesible. La utilización de columnas de laboratorio para modelar la ecología del fitoplancton se han descrito préviamente por Strickland et al.(1969) y Andersen y Nival (1989). Margalef (1963) proponía el estudio de la succesión y distribución del fitoplancton marino en una columna de laboratorio. Booker et al. (1976, 1979 y 1981) presentaban unos trabajos sobre la migración de la cianobacteria Anabaena flos aquae en relación a la disposición de nutrientes, intensidad de luz, ... en una columna de laboratorio estratificada de 2 $\mathrm{m}$ de largo por $0.45 \mathrm{~m}$ de diámetro. Heaney et al. (1989) publicaban otros estudios de ecología marina con la diatomea Asterionella formosa en otra columna de laboratorio de grandes dimensiones, $4 \mathrm{~m}$ de largo por 0.25 m de diámetro, estratiticada térmicamente.

La columna de laboratorio que se presenta en este trabajo pretende modelar los procesos que suceden en el hipolimnion de los lagos eutróficos y que comportan el establecimiento de poblaciones de bacterias fototróficas del azufre. La columna de Winogradsky modificada és una columna de laboratorio que incorpora a la columna de Winogradsky tradicional para el estudio de las poblaciones de bacterias fototróficas del azufre, las metodologias de las columnas citadas anteriomente para estudios de ecofisiologia.

El objetivo de nuestro trabajo es determinar el desarrollo de las poblaciones de bacterias fototróficas del azurre y la evolución de diferentes variables limnológicas en dos columnas de Winogradsky modificadas. La diferencia entre ambas radica en el establecimiento de un ciclo de iluminación, la presencia de mayor volumen desedimento y la mayor temperatura del agua hipolimnética en la segunda columna en relación a la primera.

\section{MATERIAL Y METTODOS}

La columna de Winogradsky modificada consiste en un cilindro de vidrio de $130 \mathrm{~cm}$ de largo por $15 \mathrm{~cm}$ de diámetro cerrado por su parte inferior (Fig. 1). Dispuesta verticalmente dispone de mecanismos eléctricos para el establecimiento de gradientes térmicos (Pibemat et al., 1991). Elmétodo de rellenado de la columna es el utilizado tradicionalment para las columnas de Winogradsky (Schlegel, 1987).

El agua se obtuvo de la sugéncia de la riera Castellana (Banyoles, Girona). Este agua presenta las particularidades de una elevada conductividad $(1800 \mu \mathrm{S} / \mathrm{cm})$ debida a una alta concentración de sulfatos (1gL) y una baja concentración de oxigeno (2 $\mathrm{mg} /$ ) disuetto (Abellà 1980, Garcia-Gil et al. 1985).

El sedimento para la construcción de las dos columnas proviene del área de Banyoles (Girona). En la primera columna de Winogradsky se colocaron $10 \mathrm{~cm}$ de sedimento en la parte inferior de la columna y la luz se

Fig. 1. Esquema de la columna de Winogradsky utilizada en este trabajo.

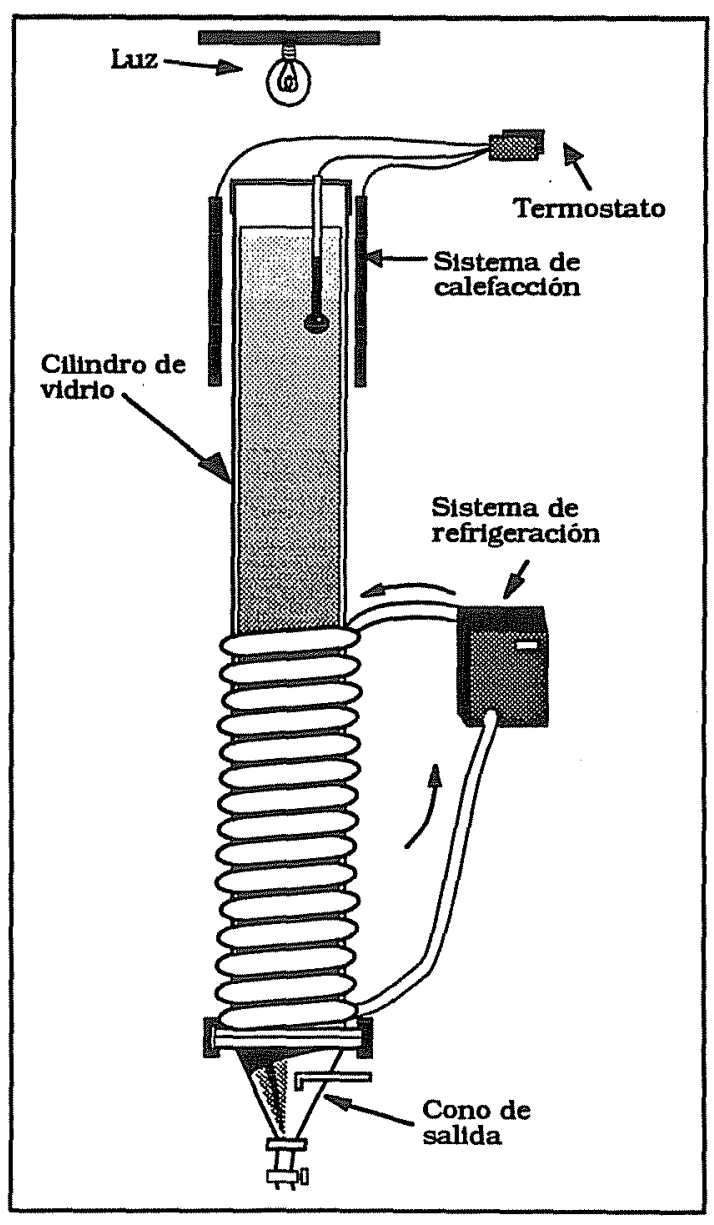


en la parte inferior de la columna y la luz se mantuvo con una bombilla de 100 W constante. La segunda columna se construyó con $30 \mathrm{~cm}$ de sedimento y un ciclo de luz/oscuridad de 12 horas.

La temperatura del agua del hipolimnion era de $15{ }^{\circ} \mathrm{C}$ en la primera columna $y$ de $25^{\circ} \mathrm{C}$ en la segunda columna.

El análisis de las variables físicas y químicas se ha realizado de la siguiente forma:

La temperatura y la conductividad se han medido con termómetro CRISON T-637 y conductivímetro CRISON 523 respectivamente.

El pH con pHmetro ORION, el potencial redox con electrodo de platino METROM modelo 6.0401 .100 , la concentración de oxígeno con Oxímetro YELLOW SPRINGS INSTRUMENTS 57 y la concentración de $\mathrm{H}_{2} \mathrm{~S}$ por método colorimétrico del azul de metileno (Pachmayer, 1960).

El estudio de los parámetros biológicos se ha efectuado mediante análisis de los pigmentos, se tomaba de 5 a $10 \mathrm{~mL}$ de muestra de la columna y se filtraba en filtro de membrana SARTORIUS (0.45 $\mu$ m diámetro poro) cubierto con una fina lámina de $\mathrm{MgCO}_{3}(2.5 \%)$. Las células retenidas en la línea de carbonato magnésico se resuspendian en acetona $90 \%$ (Montesinos, 1982). Después de $12-24$ horas el extracto se centrifugaba y el sobrenedante se analizaba espectrofotométricamente.

Las células se observaban al microscopio ZEISS de epilluorescencia y contraste de fases.

\section{RESULTADOS Y DISCUSION}

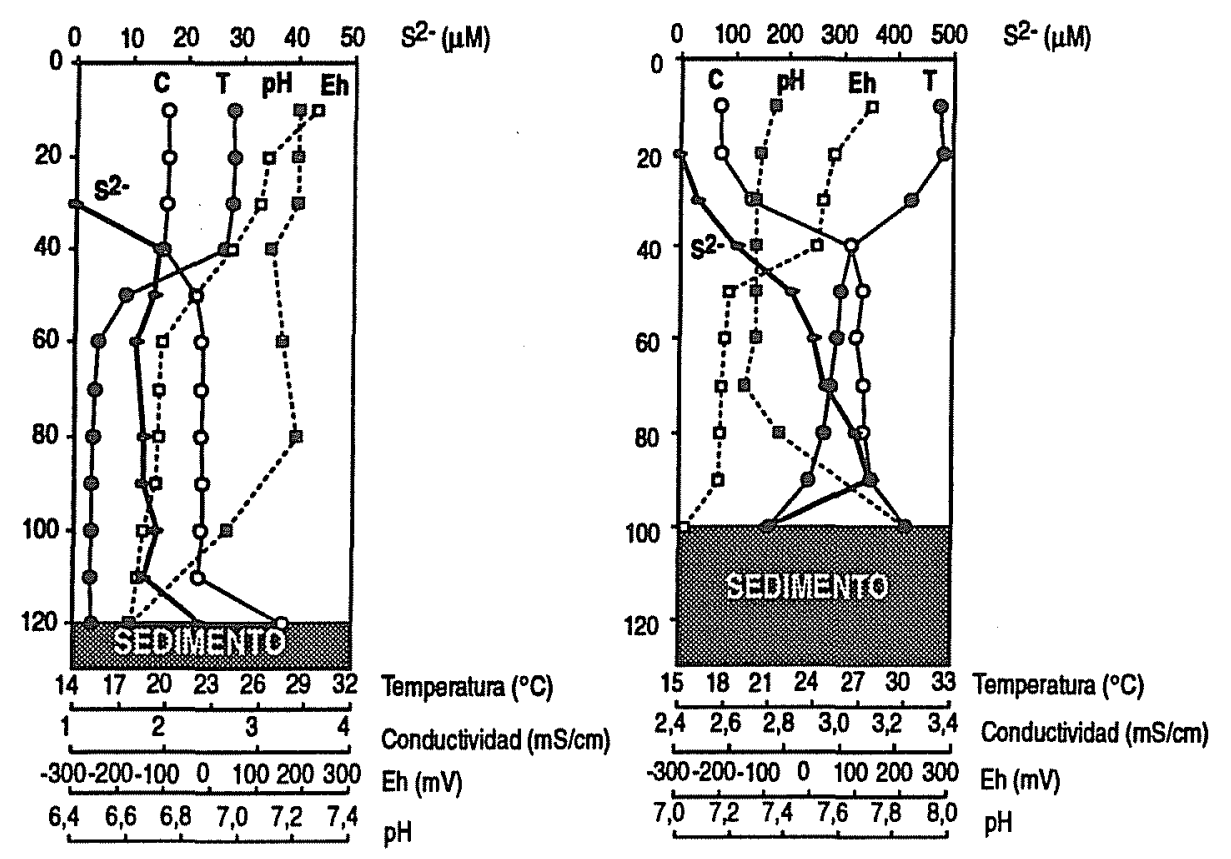

Fig. 2 Representación de los perfiles verticales de las dilerentes variables limnológicas seguidas en las dos columnas de Winogradsky modificadas. 
Las dos columnas se estudian durante un periodo similar de tiempo. Los perfiles de las variables físicas y químicas se representan en la Fig. 2. La zona con trama en la parte inferior de la columna, representa la potencia de sedimento utilizado en ambos experimentos. El seguimiento de las variables limnológicas presentaba diferencias en relación a la concentración de sulfhídrico, mayor en la columna con más sedimento. En la primera columna la concentración de $S^{2}$ era inferior a los $50 \mu \mathrm{M}$, se observaba una acidíficación en las proximidades del sedimento (de 7.2 a 6.6). Mientras que en la segunda columna con concentraciones de $S^{2-}$ superiores a 400 $\mu \mathrm{M}$, se observaba una basificación, de 7.2 a 7.8. La acidíficación cerca del sedimento se puede explicar por la presencia de sustancias ácidas (sulfhidrico, amoniaco,etc.) liberadas desde el sedimento y acumuladas en esta zona. Esta zona cercanaal sedimento se denomina "pre-sedimento" (Riera 1987) y se caracteriza por presentar particularidades más propias del agua intersticial que del agua libre en la columna. La viscosidad del agua en esta zona aumenta por la presencia de sustancias que han difundido desde el sedimento y la velocidad de sedimentación de las partículas de la columna de agua disminuye, por lo que se forma una zona de acumulación importante.

El carácter básico, encontrado en la segunda columna se explicaria por la actividad metabólica de Chlorobium limicola. En experimentos de laboratorio, se ha descrito que el metabolismo de esta especie basifica el medio en el que crece (Brugada 1986).

En el primer experimento, las condiciones de iluminación eran de 24 horas/luz y la temperatura del hipolimnion se mantenía a $15^{\circ} \mathrm{C}$, la población de bacterias fototróticas verdes del azufre desarrollada fue Chlorobium limicola f. thiosulfatophilum. Esta especie presenta abundante mucosidad que le sive para retener el $S^{2 *}$ y el $S^{\circ}$ (Brugada 1986) obteniendo asi ventaja en estas condiciones de bajas concentración de sulthidrico. Además del $\mathrm{S}^{2-}$ puede utilizar tiosulfato como aceptor teminal de electrones en su fotosintesis (van Gemerden 1981).

La Fig. 3 representa la evolución de la turbidez en el primer experimento, debida principalmente al crecimiento de poblaciones de bacterias fototróficas del azufre, en el $6^{\circ}$ intervalo de tiempo, bajo la termoclina se localiza Thiocapsa roseopersicina. Esta especie se mantiene hasta el octavo intervalo de tiempo. Elaumento de

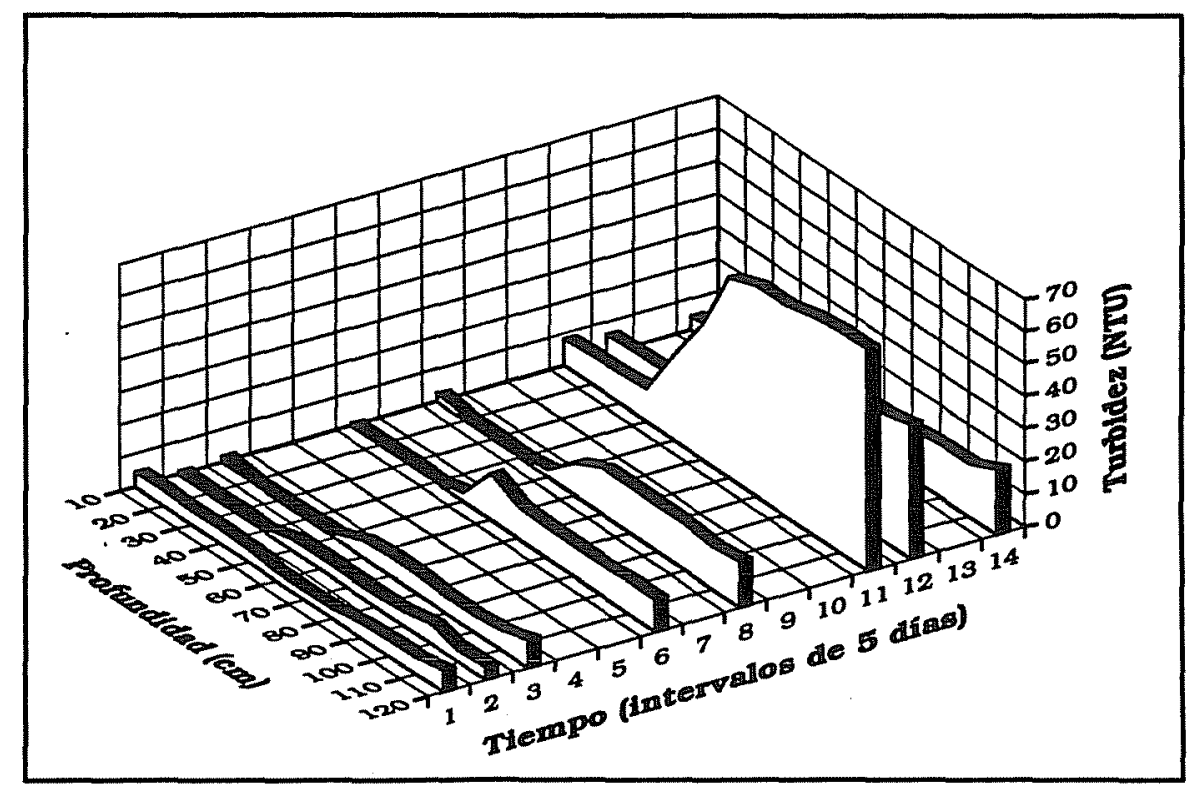

Fig. 3. Representación espacio-temporal de los perfiles de turbidez medidos en el primer experimento. 
la turbidez se debe al desarrollo de la población de Chlorobium limicola f. thiosulfatophilum quien ocupa la totalidad de la columna en su parte inferior, a partir del $8^{\circ}$ intervalo de tiempo. La presencia de las Cromatiáceas en la columna es muy corta (aprox. 15 dias).

En el segundo experimento, la iluminación seguía un ciclo de 12 horas luz/oscuridad y la temperatura del hipolimnion era de $25^{\circ} \mathrm{C}$. La población desarrollada es Chlorobium limicola. Esta especie al crecer basifica el medio en condiciones de laboratorio (Brugada 1986, Van Gemerden 1987) por lo que puede ser la responsable de este cambio en el pH de la columna.

En las Fig. 4 y 5 se representan la evolución de las concentraciones de los pigmentos fotosintéticos pertenecientes a la población de Chlorobium limicola. En la Fig. 4 se observa una aparición cerca del sedimento del carotenoide clorobacteno, a partir del los 15 días. A los 30 días la población ocupaba todo el volumen de agua posible. La distribución vertical del clorobacteno forma dos máximos, uno en la zona inferior de la termoclina y un segundo a más profundidad. Al principio del estudio, el máximo en la zona de la termoclina presentaba mayor concentración de clorobacteno, peró al final, el valor máximo se localiza cerca del sedimento. La concentración máxima de clorobacteno en este experimento fue de 70 U.A.J.

El perfil vertical de la concentración de bacterioclorofila (Fig. 5) sigue el mismo patrón que el clorobacteno en la columna de Winogradsky modificada. El máximo bajo la termoclina indicaria la población fotosintéticamente activa, mientras que el máximo cerca del sedimento sería consecuencia de la acumulación por sedimentación de la columna en la zona del "pre-sedimento".

La termoclina era de $30 \cdot 45^{\circ} \mathrm{C} / \mathrm{m}$ en ambos experimentos, éste valor es del orden de 10 veces superior a los gradientes témicos observados en condiciones naturales. El potencial de óxido-reducción paralelamente a la cantidad de sedimento y a la concentración de sulfhidrico medido, es más negativo en el segundo experimento.

La presencia de $S^{2-}$ en la columna de agua tiene una duración entre 50 y 70 días, independientemente de la cantidad de sedimento presente; durante los cuales, las poblaciones de bacterias fototróticas se desarrollan.

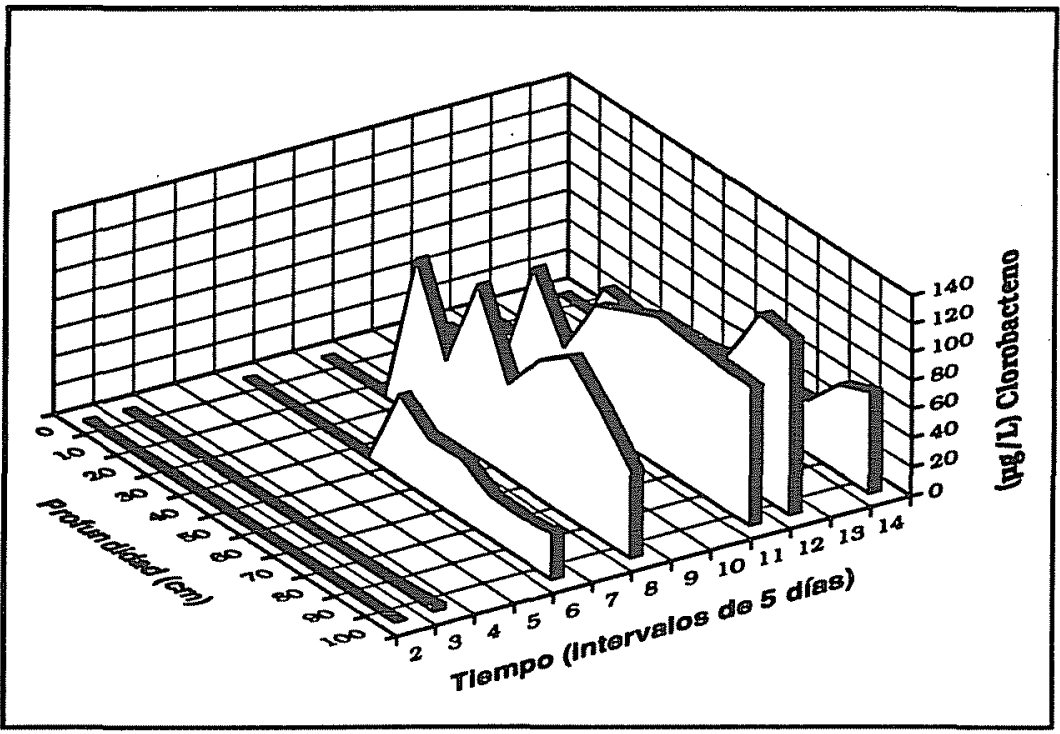

Fig. 4. Representación espacio-temporal de los perfiles verticales de la concentración del carotenoide clorobacteno en la segunda columna de Winogradsky modificada. Se observa su aparición a partir del tercer intervalo de tiempo en el fondo de la columna para posteriomente, ocupar todo el volumen de agua del hipolimnion. 


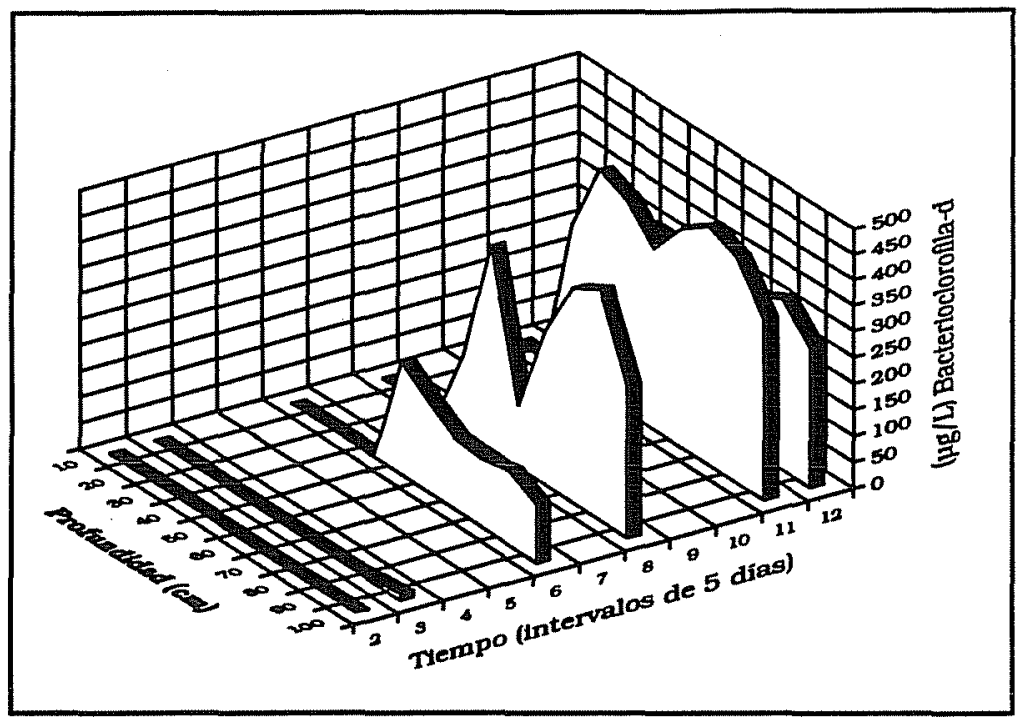

Fig 5.Representación espacio-temporal de los perfiles de concentración de bacterioctorofila de la población de Chjorabium limicola desarrollada en la segunda columna de Winogradsky modificada.

\section{CONCLUSIONES}

Con estos resultados se puede resumir que la concentración de sulthídrico medida en el agua de la columna, depende de la cantidad de sedimento y de la temperatura a la que se encuentra. Si hay $10 \mathrm{~cm}$ de sedimento a $15^{\circ} \mathrm{C}$, la cantidad máxima de sulthidrico medida és $50 \mu \mathrm{M}$ y si hay $30 \mathrm{~cm}$ de sedimento a $25^{\circ} \mathrm{C}, \mathrm{se}$ miden hasta $500 \mu \mathrm{M}$.

El ciclo de iluminación o la temperatura se relacionarian con la presencia de Cromatiáceas, en la segunda columna no se ha detectado su presencia. El límite de luz que permite crecimiento en las bacterias fototróficas verdes del azuire frente a las rojas es de 15 - 45 Lux (Bielb y Pfennig 1978).

El crecimiento de las bacterias fototrófias verdes del azufre es mury rápido ( 14 - 20 días de tiempo de generación en la laguna del Vilar, Montesinos 1982; 16 días en CIV del lago de Banyoles, Garcia-Gil et al. 1987) en relación al de las Cromatiáceas (tiempo de generación de 23 dias, Montesinos 1982).

La mayor concentración de sulfhidrico medido en la segunda columna junto con una mayor afinidad de las bacterias fototróficas verdes del azuire por este sulfhidrico y una mayor tasa de crecimiento, podrian explicar que no se hayan observado poblaciones de Cromatiáceas en esta columna de Winogradsky modificada. Las poblaciones de Cromatiáceas y de bacterias verdes del azufre Chlorobium limicola f thiosulfatophilum pueden coexistir bajo condiciones limitantes de sulthidrico (van Gemerden 1987).

Aunque la procedencia del sedimento y del agua en las dos columnas es la misma, la físiología de las poblaciones de microorganismos fototróficos del azufre desarrollada són muy diferentes. Chlorobium limicola $f$ thiosulfatophilum aparecida en la primera columna presenta características oligosulfidófilas, mientras que la enriquecida en la segunda columna, Chlorobium limicola es más sulfidófila.

La reducción de sulfatos tiene lugar en el sedimento y en la columna de agua libre (Brugada, 1986), ésta sullatorreducción origina la presencia de sulthidrico en la columna de agua que pueden consumir las bacterias fototróficas del azufre. Este sulthidrico se detecta en la columna de agua desde el establecimiento de la anoxia 
en cantidades crecientes hasta el desarrollo de las poblaciones de microoganismos. A partir de los 70 días de funcionamiento de la columna deja dedetectarse presencia del sulthídrico en la columna de agua y al mismo tiempo, las poblaciones de bacterias fototróficas del azufre sedimentan y desaparecen.

\section{BIBLIOCRAFIA}

Abellà, C. A. 1980. Dinámica poblacional comparada de bacterias fotosintéticas planctónicas. Tesis doctoral. Univ. Autónoma de Barcelona.

Andersen V. y P. Nival. 1989. Modelling of phytoplankton population dynamics in an enclosed water column.ل. mar. biol. Ass. U.K., 69: 625-646.

Biebl H. y N. Pfennig, 1978. Grownth yields of green sulfur bacteria in mixed cullures with sulfur and sulfate reducing bacteria. Arch. Microbiol. $117: 9-16$.

Booker,M. J.; M.J., Dinsdale y A. E. Walsby,1976. A continuously monitored column for the study of stratification by planktonic organisms. Limnol, \& Oceanegr., 21 (6): 915-919.

Booker M.J. y A. E. Walsby, 1979. The relative form resistance of strainght and helical blue-green algal fiaments. Br. Phycol.J. 14: 141-150.

Booker,M. J. y A. E. Walsby, 1981. Bloom formation and stratification by a planktonic blue-green alga in an experimental water column. Br. Phycol. 16:411-421.

Brock T.D. y M.T. Madigan. 1988. Biology of Microorganisms. Prentice Hall. New Jersey.

Brugada, D. 1986. Metabolisme del solre ifunció destoxificadora dels bacteris fototrófics en lestanvol del Vilar (Banyoles). Tesina de Licenciatura. Univ. Auton. Barcelona.

Garcia Gil,J. ; R.C. Brunet . y C. A. Abellà. 1985. Estudi de l'evolució dels estanyols de la Riera Castellana (Banyoles): Estanyol Nou, Sisó i Brollador Scientia Gerundensis, 11: 81-90.

Garcia Gil,J.;R.C. Brunet y C. A. Abellà. 1987. Incidencia de la inestabilidad de la meromixis en Banyoles IV (Lago Banyoles, Girona) en la dinámica poblacional de bacterias fototróficas del azufre. Actas del IV Congreso Español de Limnología. Sevilla pp:85-94.

Heaney,S. L. ; M.C. Davey, y A.S. Brooks, 1989. Formation of sub-surface maxima of a diatom within a stratified lake and in a laboratory column. d. of Plankton Research, 11 (6): 1169-1184.

Margalef, R. 1963.Modelos simplíficados del ambiente marino para el estudio de la sucesión y distribución del fitoplancton y del valor indicador de sus pigmentos. Invest. Pesg. 23: 11-52.

Montesinos, E. 1982. Ecofisiología de la folosintesis bacteriana. Ph. D. Thesis. Universitat Autònoma de Barcelona.

Pachmayer F. 1960. Vorkmmen and bestimmungvon Schefelverbindunger in Minerawasser. Ph. D. Thesis Univ. München.

Pibémat, I.V. , J.L. Garcia Gil y C. A. Abellà, 1991. Descripció d'un model experimental de columna de Winogradsky. Paràmetres tísics i quimics. Scientia gerundensis, 17: 55-62.

Riera., X.G. 1987.Cicle limnològic i ecologia de les poblacions de bacteris fototròfics en la llacuna costanera de "La Massona" (Alt Empordà. Girona). Tesina de Licencialura. Univ. Autón. Barcelona.

Schlegel, H.G. 1987. General Microbiology. Cambridge Univ. Press.

Strikland, J. D.; O. Holm-Hansen, R.W. Eppley y R.T. Linn, 1969. The use of a deep tank in phytoplankton ecology. 1. Studies of growth and composition of phytoplankton groups at low nutrients levels. Limnol. Oceanogr. 14: 23-34.

van Gemerden, H. 1981. Coexistence of Chlorobium an Chromatium in a Sulphide-Limited Continuous Culture. Arch. Microbiol., 129: 32-34.

van Gemerden, H. 1987. Competition between purple sulphur bacteria and green sulphur bacteria. Role of sulfide, sulfur and pysulfides. Acta Academica Aboensis .47 (2): 13-27. 